\section{Incentivo ao aleitamento materno no Brasil: evolução do Projeto Carteiro Amigo da Amamentação de 1996 a 2002}

\section{Incentive to breast-feeding in Brazil: progress of the Friendly Postman Breast- feeding Program from 1996 to 2002}

Maria de Fátima Moura de Araújo 1

Adriana Del Fiaco 2

Eline Heringer Werner 3

Bethsáida de Abreu Soares Schmitz 4

1 Programa de Aleitamento Materno. Saúde da Criança. Ministério da Saúde. Esplanada dos Ministérios, Bloco G, Ed. Sede, $6^{\circ}$ andar. Brasília, DF, Brasil. CEP: 70.058-900.

E-mail: fmaraujo@tba.com.br; fatima.araujo@saude.gov.br

2-4 Departamento de Nutrição. Universidade de Brasília, DF.

\begin{abstract}
Objective: to analyze the progress of the Friendly Postman Breast-feeding in the years of 1996 to 2002 in Brazil.

Methods: a descriptive study was accomplished. The data was collected through reports and telephone contacts with the people responsible for the Project in the States where the Project was implemented.

Results: the Ministry of Health implemented the Project in 1999 in eight states of the Brazilian Northeast where 3.000 postmen were trained and 665.000 children under one year old and pregnant women were potentially benefitted. In the year 2000 the project trained 6.100 postmen in the Northern, Mid-West and Northeast regions, conveying information to approximately 1.000.000 mothers of children under one year old and to pregnant women as well. In the years of 2001 and 2002 the project was extended to the rest of the country. In 200116.500 postmen participated, benefitting 2.900.000 children under one year old and pregnant women as well. In 200323.400 postmen were trained, beneficiaries were estimated in approximately 3.400.000.

Conclusions: this projet is growing throughout the country and has conquered the trus of the people, of the partners involved and is strategically important to encourage breastfeeding in the country.
\end{abstract}

Key words Evaluation, Breast feeding, Outcome assessment (health care)

\section{Resumo}

Objetivos: analisar a evolução do Projeto Carteiro Amigo nos anos de 19962002 no Brasil.

Métodos: foi realizado estudo descritivo. Os dados foram coletados por meio de relatórios e de contatos telefônicos com os setores responsáveis nos estados.

Resultados: o Ministério da Saúde implantou o Projeto, em 1999, em oito estados do Nordeste brasileiro onde foram treinados 3.000 carteiros e potencialmente beneficiadas 665.000 crianças menores de um ano e gestantes. No ano de 2000 o projeto treinou 6.100 carteiros das regiões Norte, CentroOeste e Nordeste, que levaram informações para cerca de 1.000.000 de mães de crianças menores de um ano e gestantes. Nos anos de 2001 e 2002 o projeto aconteceu em todo o Brasil. Em 2001 participaram 16.500 carteiros beneficiando 2.900 .000 crianças menores de um ano e gestantes. Em 2002, foram treinados 23.400 carteiros, estimando-se cerca de 3.400 .000 os beneficiários.

Conclusões: esse projeto, em processo crescente no país, conquistou a confiança da população, e dos parceiros envolvidos, sendo uma estratégia importante para incentivar a prática da amamentação no pais.

Palavras-chave Avaliação, Avaliação de resultados (cuidados de saúde), Aleitamento materno 


\section{Introdução}

No Brasil, até o início de 1980, as atividades de incentivo ao aleitamento materno aconteciam de forma isolada e envolviam, sobretudo, o setor saúde. Em 1981, foi criado o Programa Nacional de Incentivo ao Aleitamento Materno (PNIAM), no Instituto Nacional de Alimentação e Nutrição (INAN), autarquia do Ministério da Saúde, que passou a ser o órgão responsável pelo planejamento de ações de promoção, proteção e apoio ao aleitamento natural no país, conforme Araújo. 1

Com a extinção do INAN o Programa de Aleitamento Materno foi inserido, a partir de junho de 1998, na área de Saúde da Criança do Ministério da Saúde, que passou a implementar as ações já existentes, e a implantar outras, no sentido de melhorar os índices de aleitamento materno no país.

A política de aleitamento materno no Brasil tem envolvido diversas ações de promoção, proteção e apoio ao aleitamento materno, com o objetivo de reduzir a morbi-mortalidade infantil e melhorar a qualidade de vida das crianças brasileiras.

Diversas são as ações de aleitamento materno realizadas com sucesso no país. Pode-se citar a Iniciativa Hospital Amigo da Criança; os Bancos de Leite Humano; o monitoramento e a fiscalização da Norma Brasileira de Comercialização de Alimentos para Lactentes, Crianças de Primeira Infância, Bicos, Chupetas e Mamadeiras; a capacitação de profissionais de saúde e de outros profissionais em aleitamento materno; o Método Canguru; a fiscalização dos direitos da mulher trabalhadora que amamenta; as comemorações da Semana Mundial de Aleitamento Materno, o Projeto Bombeiros da Vida também conhecido como Bombeiro Amigo, e o Projeto Carteiro Amigo da Amamentação. 1

Todo esse trabalho tem sido coordenado e desenvolvido pelo Ministério da Saúde do Brasil de forma integrada e em parceria com as diversas instâncias do setor saúde, com universidades, organismos internacionais, organismos não governamentais, sociedades de classe, Ministério do Trabalho, corpo de bombeiros, órgãos de defesa do consumidor, parceiros do terceiro setor e o Ministério das Comunicações. ${ }^{1}$

Os resultados da Pesquisa de Prevalência de Aleitamento Materno nas capitais brasileiras e no Distrito Federal, realizada em 1999, têm apontado, sobretudo para os formuladores de políticas de saúde, a necessidade de realização de campanhas, projetos e parcerias, com o objetivo de informar à comunidade sobre a importância da amamentação, visando a melhoria dos índices de aleitamento mater- no no Brasil.2

Essa pesquisa revelou que o desmame precoce ainda é um importante problema de saúde pública no Brasil. No primeiro mês de vida, $53,1 \%$ das crianças mamam exclusivamente no peito, ocorrendo a partir daí uma brusca redução nos índices de aleitamento exclusivo, sendo de $9,7 \%$ a freqüência da amamentação exclusiva no intervalo de 151 a 180 dias. A duração mediana de aleitamento materno exclusivo no Brasil foi de 23,4 dias. ${ }^{2}$

Excetuando as capitais da região Norte do país, todas as demais capitais brasileiras apresentaram duração mediana de aleitamento materno inferior a 12 meses. Em todas as capitais estudadas, a duração mediana de aleitamento materno exclusivo foi inferior a 70 dias. $^{2}$

Quando se comparam os dados de aleitamento materno exclusivo em menores de quatro meses ao longo dos anos, observa-se um aumento importante nessa prática no Brasil, passando de uma freqüência de 3,6\% em 1986 (dados rurais e urbanos do Brasil) para 35,6\% no estudo de 1999 (dado urbano).1,2

O fortalecimento das ações de promoção, proteção e apoio ao aleitamento materno é de fundamental importância para a melhoria dos índices de aleitamento materno. Aumentar a taxa de amamentação exclusiva e a duração mediana de aleitamento materno tem sido um desafio no mundo, e em especial no Brasil.

Dentre as ações voltadas para a obtenção deste propósito, destaca-se nesse estudo o Projeto Carteiro Amigo da Amamentação. Trata-se de um projeto de parceria entre o sistema de saúde e a Empresa de Correios e Telégrafos (ECT), que visa informar a comunidade sobre a importância e as vantagens do aleitamento materno para a saúde da mãe e da criança, com o objetivo de incentivar a prática do aleitamento materno exclusivo até os seis meses e do aleitamento materno continuado até os dois anos de idade ou mais, como estratégia para reduzir a desnutrição e a morbi-mortalidade infantil e melhorar a qualidade de vida das crianças brasileiras.

Os carteiros participam no Projeto Carteiro Amigo da Amamentação como força auxiliar dos órgãos de saúde, divulgando as vantagens da amamentação natural, orientando nutrizes e gestantes, e distribuindo nos domicílios onde residem gestantes e crianças menores de um ano, um folder produzido pelo Ministério da Saúde, com os dez passos para se obter sucesso no aleitamento materno.

Assim, a rotina diária de entrega de correspondências, tem-se tornado por meio desse Projeto, também um exercício de conscientização popular. Valendo-se da credibilidade e da inserção dos carteiros em co- 
munidades carentes, o Programa transforma esses profissionais em multiplicadores de informação sobre o aleitamento materno, sobretudo em regiões onde a população é mais pobre e tem menos acesso à informação.

O Projeto Carteiro Amigo nasceu no Ceará em 1996, como uma das estratégias estabelecidas pelo governo para combater a desnutrição e a mortalidade infantil no estado. Até o início da década de 80, os índices de mortalidade infantil eram alarmantes no Ceará. No ano de 1987, dados da Secretaria Estadual de Saúde registraram que para cada 1.000 crianças nascidas no estado, 106 morriam antes de completar um ano de idade. 3 Para reverter esse quadro, o governo do Estado, em 1987, criou o programa Viva Criança, que entre outros objetivos, priorizou ações de incentivo ao aleitamento materno, como uma poderosa arma contra a desnutrição infantil. ${ }^{3}$

Conscientes da importância do aleitamento materno no combate à mortalidade infantil, entidades, empresas e organizações não governamentais se mobilizaram no Ceará para informar e apoiar as mães sobre a importância do aleitamento natural, criando o Projeto Carteiro Amigo. ${ }^{3}$

A análise histórica dos principais resultados do Projeto Carteiro Amigo no Ceará, desde 1996, revela ter sido o treinamento dos carteiros realizado durante o primeiro semestre de 1996 por equipes da Secretaria de Saúde, em seu próprio local de trabalho. Todo o contingente de carteiros existente naquela época em Fortaleza foi capacitado, ou seja, 585 indivíduos. Aproximadamente 100.000 folders foram distribuídos nas visitas domiciliares. 3

A experiência e os resultados positivos do Projeto Carteiro Amigo no Ceará motivaram o Ministério da Saúde a desenvolver uma parceria com o Ministério das Comunicações, por meio da ECT.

No período de um a 31 de outubro de 1999, essa estratégia foi promovida nos nove estados da região Nordeste, envolvendo inicialmente as capitais, algumas cidades do entorno e cidades de grande porte dessa região, que dispunham de Centro de Distribuição Domiciliar (CDD).4-6 Os carteiros então, foram as ruas, vestindo camisetas com a serigrafia: "Amamentação: bom para a mãe. Melhor para o bebê", orientando e distribuindo os folders nas residências onde encontravam gestantes e crianças menores de um ano.

Esse Projeto tem recebido diversas manifestações de reconhecimento. Em abril de 1997, obteve repercussão internacional com a divulgação do projeto pela British Broadcasting Corporation (BBC) de Londres. Em 2000, recebeu o prêmio "Top Social" da Associação Brasileira dos Dirigentes de Vendas e
Marketing do Brasil (ADVB), e em 2001, recebeu o prêmio "Hélio Beltrão", no VI Concurso de Inovações na Gestão Pública Federal.4-8

A proposta de uma parceria tendo os carteiros, profissionais que gozam de alta credibilidade junto às comunidades, como protagonistas de uma ampla ação social em beneficio da saúde da criança, é de grande relevância, visto que esses atuam como agentes de transformação, disseminando em milhares de lares em todo o Brasil, informações e materiais que beneficiam a saúde e a nutrição da criança brasileira.

O objetivo do presente estudo é analisar a evolução e expansão do Projeto Carteiro Amigo da amamentação no Brasil desde seu início, em 1996, até o ano de 2002.

\section{Métodos}

É um estudo descritivo, onde foram coletadas informações a respeito da história e da expansão do Projeto Carteiro Amigo nos anos de 1996 a 2002 no Brasil.

Foi realizada coleta de informações sobre a história do Projeto, incluindo o seu início no estado do Ceará, em 1996, por meio de relatórios federais (da Área de Aleitamento Materno do Ministério da Saúde e da Empresa Brasileira de Correios e Telégrafos) e estaduais (da Secretaria Estadual de Saúde e da Empresa de Correios e Telégrafos do Ceará).3-5

Os dados sobre os municípios envolvidos, carteiros treinados, clientela alvo potencialmente beneficiada e número de folders produzidos e distribuídos no Projeto Carteiro Amigo nos anos de 1999 a 2001, foram obtidos diretamente por meio de relatórios da Área de Aleitamento Materno do Ministério da Saúde.4-8

As informações sobre o Projeto no ano de 2002 foram obtidas por meio de contatos telefônicos com as Secretarias Estaduais de Saúde, Empresas de Correios e Telégrafos dos 26 estados da Federação e do Distrito Federal e com a Empresa Brasileira de Correios e Telégrafos, que foram descritos posteriormente em relatório da área de Aleitamento Materno do Ministério da Saúde. 9

Foi solicitada aos estados a relação dos municípios que aderiram e implantaram o projeto Carteiro Amigo, e o número de carteiros treinados e atuantes no projeto em cada um desses anos. A relação dos Centros de Distribuição Domiciliar (CDD), por estado foi obtida na ECT.

O número de crianças menores de um ano e gestantes, potencialmente beneficiadas, nos municípios 
que aderiram ao Projeto, foi obtido diretamente do número de nascidos vivos no sistema DATASUS, nos anos de 1999 e 2000.10,11 Com as informações coletadas no período de 1996 a 2002, pode-se analisar a evolução e a expansão do Projeto Carteiro Amigo da Amamentação no Brasil.

\section{Resultados}

Quando se compara o número de carteiros existentes em todo o país com o número de carteiros treinados e envolvidos, observa-se na Figura 1 que, no ano de 2001, 54,5\% dos carteiros participaram dessa iniciativa. Na Figura 2 pode ser observado que o quantitativo de folders produzidos e distribuídos por meio desse projeto, no período de 1996 a 2002 aumentou em aproximadamente 10 vezes. No ano de 1996, o material educativo foi produzido pela Secretaria de Saúde do Ceará. No período de 1999 a 2002, todos os folders foram produzidos pelo Ministério da Saúde.

\section{Figura 1}

Relação do número de carteiros envolvidos no Projeto Carteiro Amigo $x$ total de carteiros existentes no Brasil em 2001.

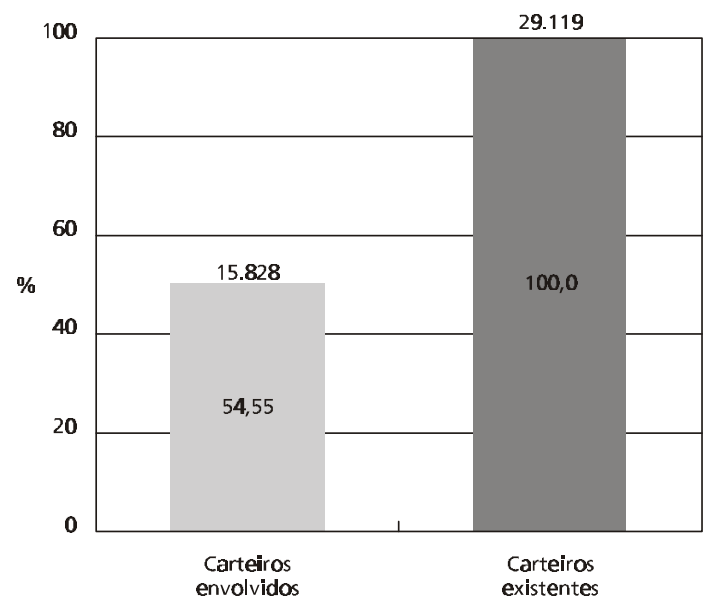

Fonte: Ministério da Saúde. Avaliação das ações programadas/executadas em aleitamento materno no ano de 2001. Brasília (DF); 2001.17

Figura 2

Quantidade de folders distribuídos por carteiros envolvidos no Projeto Carteiro Amigo no Brasil no periódo de 1996 a 2002.

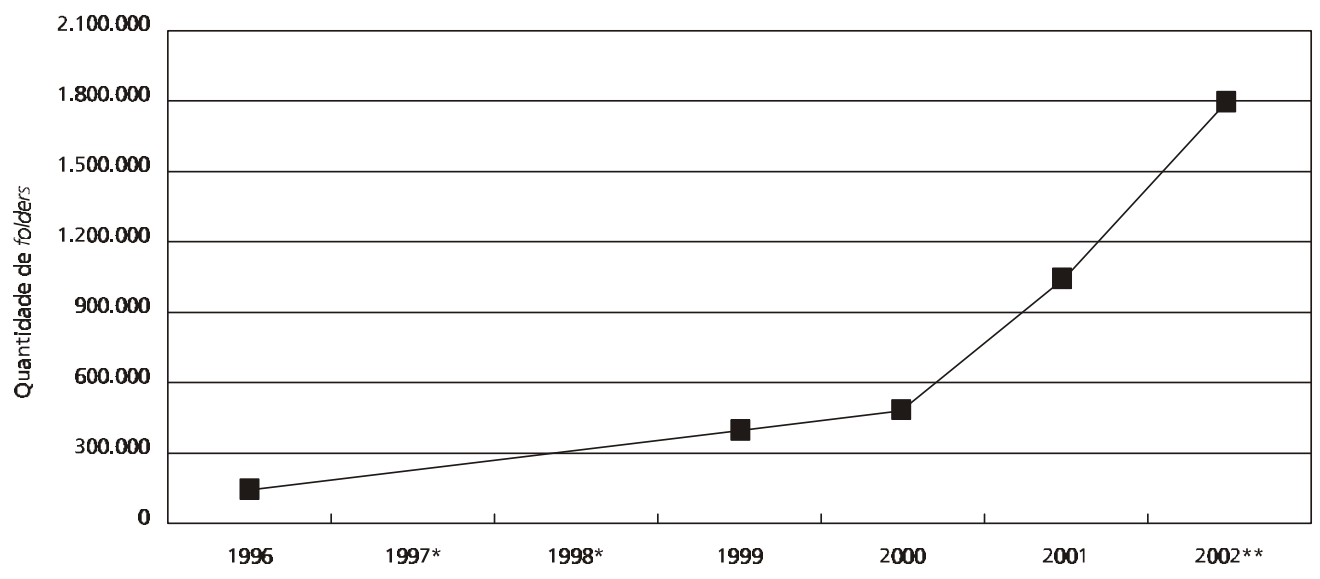

Folders distribuldos

Nos anos de 1997 e 1998, o Projeto Carteiro Amigo não abordou o tema do aleitamento materno.

Fonte: Ministério da Saúde. Projeto Carteiro Amigo: Nordeste. Brasília (DF); 1999.4; Ministério da Saúde. Projeto Carteiro Amigo. Brasília (DF); 2000.6; Ministério da Saúde. Avaliação das ações programadas/executadas em aleitamento materno no ano de 2001. Brasília (DF); 2001.7 
Dos 5.507 municípios brasileiros 468 municípios participaram do projeto em 2001 (8,5\%).7 Deve-se ressaltar que o Projeto foi idealizado inicialmente para ser implantado nos municípios que dispõem de CDD e a grande maioria dos municípios brasileiros não dispõem desse Centro.

Na Tabela 1, pode ser observado o total de municípios, o total de carteiros treinados e a população potencialmente beneficiada em cada um dos 24 esta- dos brasileiros que participaram do Projeto Carteiro Amigo da Amamentação em 2002. Verifica-se que houve a expansão do projeto para outros municípios brasileiros, participando, nesse ano, 993 municípios de 24 estados brasileiros, o que corresponde a $21 \%$ dos municípios existentes no país. Ainda em 2002, foram treinados cerca de 23.400 carteiros dos 30.883 existentes, o que correspondeu a $76 \%$ do total dos carteiros em CDD no país. 9

Tabela 1

Número de municípios e de carteiros envolvidos e população beneficiada com o Projeto Carteiro Amigo em 2002.

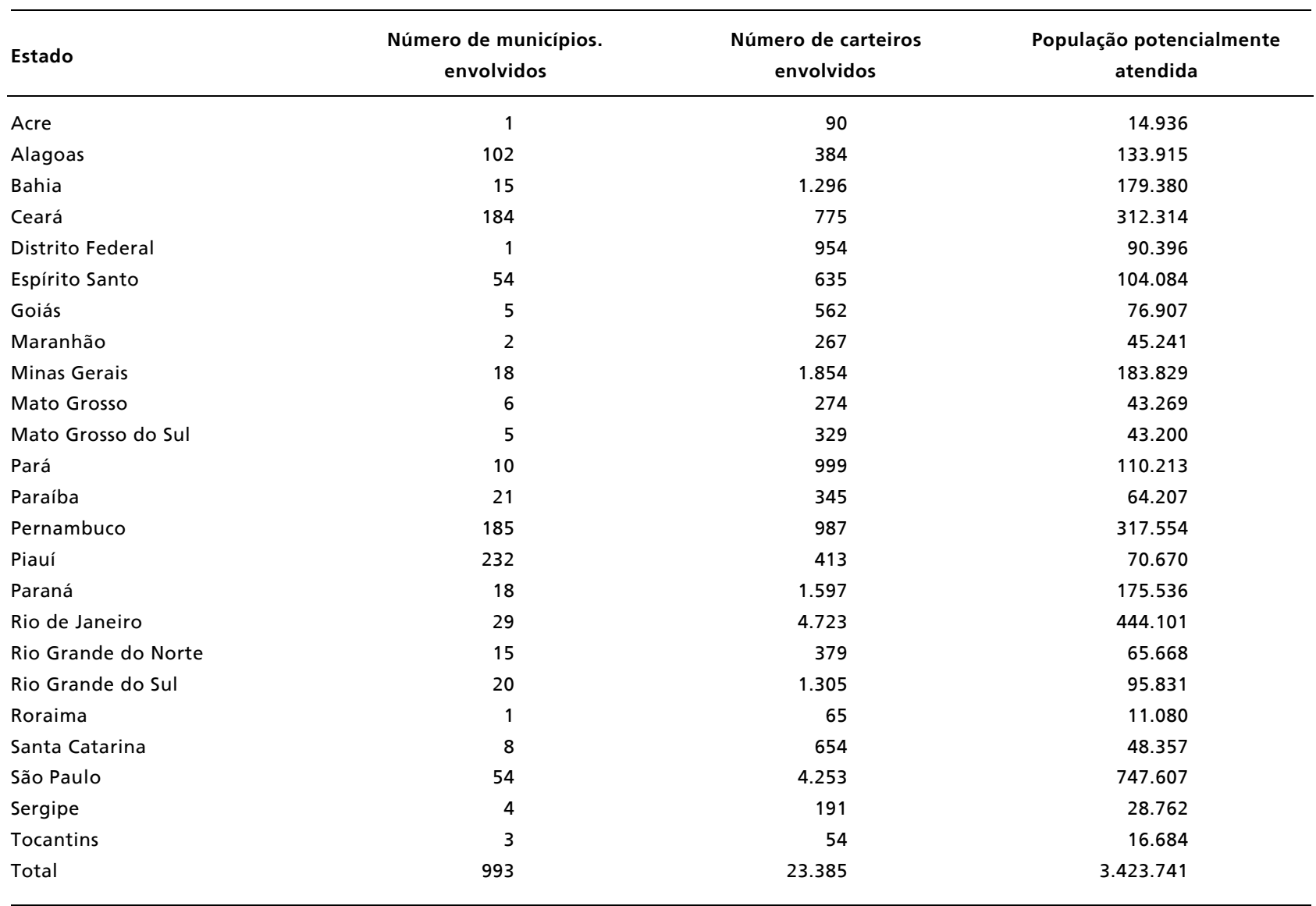

Fonte: Ministério da Saúde. Avaliação das ações programadas/executadas em aleitamento materno no ano de 2002 . Brasília (DF); 2002.9

Quando se analisa a expansão do Projeto entre os anos de 2001 e 2002, observa-se que ela ocorreu de forma gradual em alguns estados e de maneira mais rápida em outros, como por exemplo, em Pernambu- co, Santa Catarina, Paraná e Tocantins, onde o número de municípios envolvidos aumentou em duas vezes ou mais entre esses anos (Tabela 2). 
Expansão do Projeto Carteiro Amigo em alguns estados brasileiros nos anos de 2001 e 2002.

\begin{tabular}{lrr}
\hline & 2001 & 2002 \\
& Número de municípios & Número de municípios \\
\cline { 2 - 3 } & & 185 \\
\hline Pernambuco & 9 & 8 \\
Santa Catarina & 2 & 18 \\
Paraná & 5 & 3 \\
Tocantins & 1 & 15 \\
Rio Grande do Norte & 6 & 54 \\
Espírito Santo & 21 & 15 \\
Bahia & 6 & 10 \\
Pará & 4 & 18 \\
Minas Gerais & 8 & 5 \\
Goiás & 3 & 21 \\
Paraíba & 15 & \\
\hline
\end{tabular}

Fonte: Ministério da Saúde. Avaliação das ações programadas/executadas em aleitamento materno no ano de 2001. Brasília (DF); 2001.7; Ministério da Saúde. Avaliação das ações programadas/executadas em aleitamento materno no ano de 2002. Brasília (DF); 2002.9

A evolução do número de carteiros treinados e o número de crianças menores de um ano e gestantes potencialmente beneficiadas com essa ação, no período de 1999 a 2002, pode ser vista na Figura 3. Observa-se uma adesão cada vez maior dos carteiros nesse projeto. De uma participação de 3.000 carteiros em 1999, conseguiu-se treinar 23.400 carteiros em 2002, o que representa um aumento de quase oito vezes. Em relação à população alvo, houve um aumento de cerca de cinco vezes no número de crianças menores de um ano e gestantes potencialmente beneficiadas nesse Projeto entre os anos de 1999 a 2002 (Figura 3).

Quanto ao número de CDD, observou-se em 1999, que 84 CDD estiveram envolvidos no Projeto, com a participação de 3.000 carteiros treinados (Figura 3). Houve a distribuição de 380.000 folders, beneficiando potencialmente uma população de 665.000 crianças menores de um ano de idade e gestantes dos municípios envolvidos nessa região do Nordeste brasileiro (Figuras 2 e 3 ).

A Figura 4 mostra o número de municípios brasileiros e de CDD que participaram do Projeto Carteiro Amigo da Amamentação nos anos 2000, 2001 e 2002 no Brasil.

No ano de 2000, o Projeto aconteceu também no período de um a 31 de outubro e foi ampliado para atender, não apenas a região Nordeste, mas também as regiões Norte e Centro-Oeste do país. Neste ano,
57 municípios dos 19 estados dessas três regiões aderiram e participaram do projeto (Figura 4).

Dos 175 CDD existentes nos 19 estados que aderiram ao Projeto em 2000, 157 CDD participaram (Figura 4), colocando todo o seu quantitativo de carteiros à disposição do projeto, o que representou aproximadamente $90 \%$ de adesão. Cerca de 6.100 carteiros foram treinados nesse ano nos estados das regiões Nordeste, Norte e Centro-Oeste, e 500.000 folders foram distribuídos pelos carteiros nesse ano a uma população estimada em cerca de 1.000.000 de crianças menores de um ano e gestantes (Figuras 2 e 3 ).

Em 2001, o projeto foi realizado em todo o país, abrangendo pela primeira vez as regiões Sul e Sudeste, no período de um a 31 de outubro. Nesta ocasião, 358 CDD dos 730 existentes no país, foram envolvidos (Figura 4).

A redução na proporção de CDD que participaram do Projeto Carteiro Amigo da Amamentação nesse ano, quando comparado com o ano de 2000, se justifica pela grande concentração de CDD existente nas regiões Sul e Sudeste do país $(77,9 \%$ do total Brasil). Esta grande concentração de CDD, e o fato de ser esta a primeira vez da execução do Projeto nessas regiões dificultaram todo o processo de implantação, especialmente no tocante ao treinamento do grande contingente de carteiros existente. 
Número de carteiros treinados e população potencialmente beneficiada com o Projeto Carteiro Amigo no Brasil nos anos de 1999 a 2002.

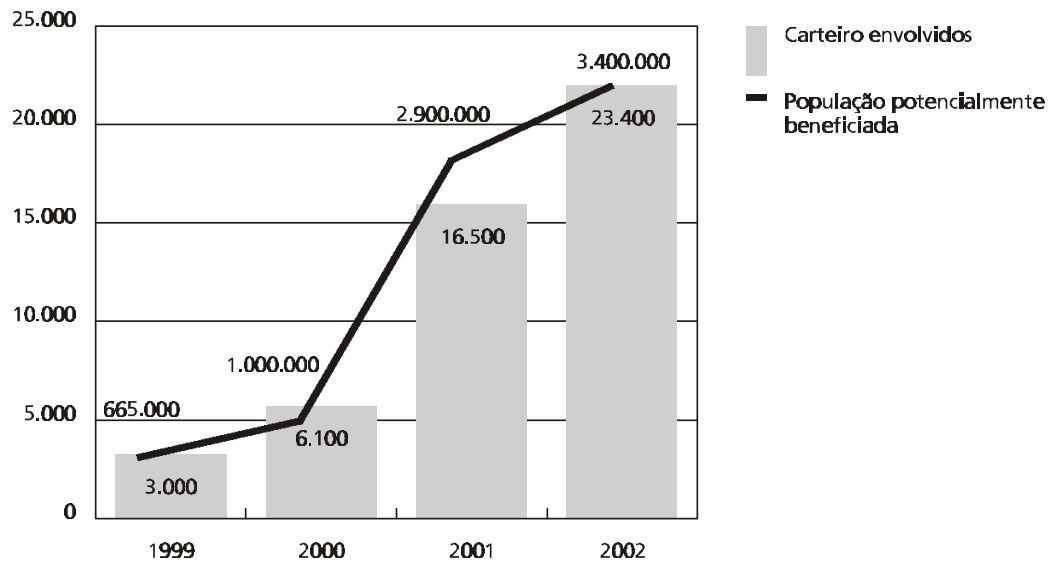

Fonte: Ministério da Saúde. Projeto Carteiro Amigo: Nordeste. Brasília (DF); 1999.4 ; Ministério da Saúde.

Projeto Carteiro Amigo. Brasília (DF); 2000.6 ; Ministério da Saúde. Avaliação das ações programadas/executadas em aleitamento materno no ano de 2001. Brasília (DF); 2001.7; Ministério da Saúde. Avaliação das ações programadas/executadas em aleitamento materno no ano de 2002. Brasília (DF); 2002.9

\section{Figura 4}

Número de municípios e de Centro de Distribuição Domiciliar (CDD) envolvidos no Projeto Carteiro Amigo da Amamentação no Brasil nos anos 2000, 2001 e 2002.

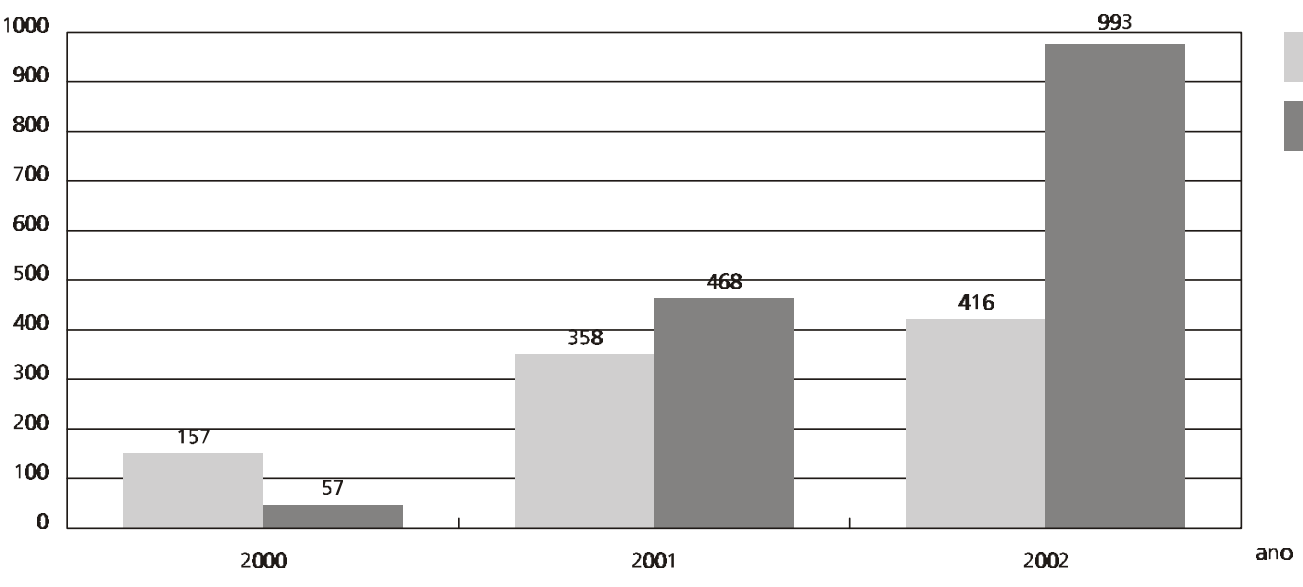

Número de CDD

Número de municípios

Fonte: Ministério da Saúde. Projeto Carteiro Amigo. Brasília (DF); 2000.6 ; Ministério da Saúde. Avaliação das ações programadas/executadas em aleitamento materno no ano de 2001. Brasília (DF); 2001.7 ; Ministério da Saúde. Avaliação das ações programadas/executadas em aleitamento materno no ano de 2002. Brasília (DF); 2002.9 


\section{Discussão}

Observa-se uma dificuldade de análise dos resultados obtidos pela avaliação dos dados do Projeto Carteiro Amigo, uma vez que esta iniciativa é inédita não só no Brasil, como em outros países, não sendo encontradas experiências similares para efeito de comparação. Neste sentido, este artigo procurou elaborar de uma forma descritiva e histórica, as várias fases de desenvolvimento do Projeto, desde sua criação em 1996 até o ano de 2002, no intuito de registrar e avaliar as ações executadas até agora.

No Brasil, tem sido demonstrado aumento importante nos índices de aleitamento materno nos últimos anos. No entanto, o país ainda se encontra muito distante de atingir a meta de aleitamento materno exclusivo recomendada, bem como de garantir que as crianças sejam amamentadas até o segundo ano de vida ou mais. ${ }^{2}$

Por essa razão, evidencia-se a necessidade de campanhas e projetos que tenham como objetivo informar a comunidade sobre as vantagens e a importância da amamentação. Ações de promoção e de apoio ao aleitamento materno, envolvendo múltiplos parceiros, têm sido realizadas pelo governo brasileiro, e devem continuar sendo estimuladas e postas em prática, para garantir, cada vez mais, a melhoria dos indicadores de aleitamento materno.

Estudos realizados no país indicam que a falta de informação das mães e da sociedade em geral, inclusive dos próprios profissionais de saúde, repercute negativamente na duração do aleitamento materno. $12-14$

Ainda, em diversos países do mundo, sejam eles industrializados ou em desenvolvimento, os profissionais de saúde têm dificuldades em fornecer um acompanhamento adequado às mães, e estas, muitas vezes, não procuram ajuda no serviço de saúde, no caso de haver intercorrências no início e na manutenção da amamentação. ${ }^{15}$

Tem sido demonstrado que leigos treinados em amamentação podem ser mais capazes de fornecer ajuda individual freqüente para as gestantes e mães, no intuito de aumentar sua autoconfiança e superar adversidades, do que o próprio serviço de saúde formal. ${ }^{15}$ Logo, torna-se necessário envolver outros setores da sociedade civil organizada, assim como outros setores estatais, extra área da saúde, no estabelecimento de parcerias para o fornecimento de apoio adequado às gestantes e mães, explorando o potencial de iniciativas à semelhança do Projeto Carteiro Amigo.

Possivelmente, a combinação do apoio domiciliar realizado por leigos, juntamente com uma ajuda mais especializada do serviço de saúde, quando se faz necessário, pode ser mais efetiva do que qualquer apoio prestado isoladamente. 15

Nesse sentido, o Projeto Carteiro Amigo da Amamentação além de inovar a participação dos carteiros em ações de saúde, tem se mostrado uma ação social efetiva de incentivo a prática do aleitamento materno no Brasil, contribuindo para aumentar o nível de informação sobre as vantagens e importância da amamentação para a saúde da mulher e da criança.

Vale ressaltar que em 2000, o projeto foi realizado nos estados de três regiões brasileiras, e que nos anos de 2001 e 2002, o projeto foi realizado nas cinco regiões do país, embora em 2002 três estados brasileiros não tenham participado do Projeto. Mesmo assim, observa-se a grande expansão que vem tendo o Projeto Carteiro Amigo da Amamentação no Brasil desde a sua implantação.

No ano de 2002, observou-se que o número de municípios integrantes do Projeto Carteiro Amigo no país, quando comparado com o ano de 2001, quase duplicou, apesar do número de CDD envolvidos não ter aumentado na mesma proporção. Esse fato deveu-se a participação no Projeto, durante esse ano, de municípios que não dispunham de CDD. ${ }^{9}$

Estima-se que cerca de 3.400 .000 crianças menores de um ano e gestantes foram potencialmente beneficiadas com o projeto em 2002. O Ministério da Saúde produziu nesse ano, 1.800 .000 folders que foram distribuídos pelos carteiros nos municípios dos estados que aderiram ao projeto. 9

Em seu início no Ceará, esse Projeto teve como objetivo a utilização dos carteiros como agentes multiplicadores de informações, que pudessem conscientizar a comunidade para a importância do aleitamento materno e do soro caseiro, visando deter os números crescentes da desnutrição e da mortalidade infantil no estado. O tema da campanha foi: "Carinho e Amamentação Não se Descartam". 3

Os carteiros receberam um treinamento de quatro horas, incluindo noções básicas sobre amamentação e técnicas de abordagem à população para a entrega de folders e colheres padrão para a elaboração do soro caseiro. Também era distribuída uma lista com endereços de todos os hospitais "Amigos da Criança" credenciados no estado, visando divulgar esses hospitais entre as gestantes. ${ }^{3}$ Posteriormente, o Projeto Carteiro implantado no Ceará foi modificado, tendo seu objetivo centralizado apenas na divulgação de informações e apoio ao aleitamento materno.

Durante toda a sua história, o Ceará, a exemplo de outros estados da região Nordeste do Brasil, tem 
lutado contra cruéis indicadores socioeconômicos oriundos da falta de uma política efetiva de desenvolvimento regional, agravados pelos fatores climáticos. 3

Em primeiro de julho de 1999, foi assinado pelo Ministério da Saúde e o Ministério das Comunicações, o primeiro Protocolo de Ação Conjunta, visando levar o Projeto Carteiro Amigo, inicialmente, aos estados do Nordeste do país.3,6

Para a viabilização do Projeto, os técnicos das Secretarias Estaduais de Saúde foram orientados por uma equipe designada pelo Ministério da Saúde, para ministrar um curso de capacitação para os carteiros a fim de padronizar o treinamento. Desde então, o Projeto Nacional de treinamento dos carteiros inclui uma carga horária que varia de duas a quatro horas, a depender da metodologia utilizada, e um conteúdo teórico - prático com aulas sobre as vantagens da amamentação, composição do leite, pega e posição corretas, freqüência da amamentação, ordenha e a importância do carteiro nesse Projeto. Ficou estabelecido que os treinamentos dos carteiros deveriam ocorrer, todos os anos, no mês anterior a realização do Projeto.

O conteúdo do folder, distribuído pelos carteiros no período de 1999 a 2002, incluía informações sobre as vantagens da amamentação e as recomendações da política nacional de aleitamento materno, além de outras informações relativas aos dez passos para o sucesso do aleitamento materno, como por exemplo, a posição e pega corretas, freqüência das mamadas, riscos do uso de chupetas, bicos e mamadeiras, ordenha, cuidados com as mamas e os direitos da mulher trabalhadora que amamenta. Quando necessário estas informações tem sido atualizadas. 16

O lançamento do Projeto Carteiro Amigo da Amamentação acontece sempre no primeiro dia das comemorações da "Semana Mundial de Aleitamento Materno" (SMAM) no país. Diversos eventos são promovidos para chamar a atenção da população para o projeto: carreatas, exposições fotográficas, concursos de cartazes, palestras, gincanas, queima de fogos e apresentações teatrais sobre o tema.

Os carteiros foram inseridos nesse Projeto como mais uma categoria profissional, habilitada para promover a amamentação no Brasil. Isto é relevante uma vez que o estudo de Melo et al.,12 indicou que quase $60 \%$ das primíparas avaliadas em Pernambuco relataram não terem recebido qualquer tipo de informação quanto à orientação sobre o aleitamento materno, apesar da elevada freqüência ao pré-natal.

Nesse sentido, a existência desse Projeto dá oportunidade às gestantes e às mães de crianças menores de um ano, para o recebimento de informações sobre as vantagens e a importância da ama- mentação, bem como o apoio e a orientação necessários para o aprendizado sobre a pega e a posição corretas e método de ordenha, entre outros. Estas orientações são básicas e essenciais para o sucesso do aleitamento materno, complementam as informações recebidas durante o pré-natal, e, em alguns locais, podem ser a única fonte de orientação para essa clientela. 12

Este Projeto de parceria entre o Ministério da Saúde e o Ministério das Comunicações, por meio da ECT, constitui exemplo marcante de ação compartilhada em prol da saúde infantil, demonstrando preocupação social, espírito de solidariedade e cidadania, e servindo de incentivo para o êxito das políticas públicas de saúde empreendidas pelo governo brasileiro.

Educar e mudar padrões culturais exige esforço constante e atividades permanentes, e para tanto, a busca de parceiros compromissados com o processo de resgate da amamentação no país é de fundamental importância neste processo.

\section{Conclusões}

Uma política nacional de promoção, proteção e apoio ao aleitamento materno está instalada no país. Considerando que o Brasil é um país de grandes dimensões e de grandes contrastes regionais, faz-se mister apoiar iniciativas que causem impacto no sentido de aumentar a prevalência do aleitamento materno exclusivo, e sua duração no país, nos diferentes municípios.

A existência deste projeto, à semelhança do Projeto Bombeiro Amigo da Amamentação, também desenvolvido em parceria entre o corpo de bombeiros e os bancos de leite humano, são fatores que têm contribuído para o reconhecimento internacional do Programa de Aleitamento Materno no Brasil.

Estas experiências comprovam que soluções criativas de parceria com outras organizações estatais, não necessariamente vinculadas à saúde, podem potencializar a disseminação e divulgação no Brasil, das informações sobre a importância e vantagens do aleitamento materno.

Espera-se, a cada ano, implantar esse projeto em um número maior de municípios brasileiros. Esta ação, para se consolidar em um país de grande extensão como o Brasil, precisa de incentivos crescentes e colaboração dos parceiros envolvidos, visando alcançar o objetivo desejado, que é a melhoria da prevalência do aleitamento materno exclusivo e continuado até os dois anos de idade ou mais, e da qualidade de vida das crianças. 


\section{Referências}

1. Araújo MFM. Situação e perspectivas do aleitamento materno no Brasil. In: Carvalho MR, Tamez RN. Amamentação: bases científicas para a prática profissional. Rio de Janeiro: Guanabara Koogan; 2002. p. 1-10.

2. Ministério da Saúde. Pesquisa de prevalência do aleitamento materno nas capitais e no Distrito Federal: relatório. Brasília (DF): O Ministério; 2001.

3. ECT (Empresa Brasileira de Correios e Telégrafos). Protocolo de ação conjunta Ministério da Saúde x Empresa de Correios e Telégrafos: Programa Carteiro Amigo - relatório. Brasília (DF): A Empresa; 1999.

4. Ministério da Saúde. Projeto Carteiro Amigo: Nordeste - relatório. Brasília (DF): O Ministério; 1999.

5. ECT (Empresa Brasileira de Correios e Telégrafos). Atividades: Programa Carteiro Amigo: relatório. Brasília (DF): A Empresa; 2000.

6. Ministério da Saúde. Projeto Carteiro Amigo: relatório. Brasília (DF): O Ministério; 2000.

7. Ministério da Saúde. Avaliação das ações programadas/executadas em aleitamento materno no ano de 2001: relatório. Brasília (DF): O Ministério; 2001.

8. Ministério da Saúde. Secretaria de Políticas de Saúde. Área de Saúde da Criança. Programas e projetos de saúde da criança: responsabilidades compartilhadas em benefício das crianças brasileiras. Rev Bras Saúde Matern Infant 2002; 2: 193-6.

9. Ministério da Saúde. Avaliação das ações programadas/executadas em aleitamento materno no ano de 2002: relatório. Brasília (DF): O Ministério; 2002.

10. DATASUS. Informações de saúde: estatísticas vitais - mortalidade e nascidos vivos. Nascimento por residência da mãe segundo município. Período de 1999. Disponível em: <http://www.datasus.gov.br/tabnet/tabnet.htm $>$. [2002 nov 14].

11. DATASUS. Informações de saúde: estatísticas vitais - mortalidade e nascidos vivos. Nascimento por residência da mãe segundo município. Período de 2000. Disponível em: <http://www.datasus.gov.br/tabnet/tabnet.htm>. [2002 nov 14].

12. Melo AMCA, Cabral PC, Albino E, Moura LMD, Menezes AEB, Wanderley LG. Conhecimentos e atitudes sobre aleitamento materno em primíparas da cidade do Recife, Pernambuco. Rev Bras Saúde Matern Infant 2002; 2: 137-42.

13. Susin LRO, Giugliani ERJ, Kummer SC, Maciel M, Benjamim ACW, Machado DB, Barcaro M, Draghetti V. Uma estratégia simples que aumenta os conhecimentos das mães em aleitamento materno e melhora as taxas de amamentação. J Pediatr [Rio de Janeiro] 1998; 74: 36875.

14. Giugliani ERJ, Rocha VLL, Neves JN, Polanczyk CA, Seffrin CF, Susin LRO. Conhecimentos maternos em amamentação e fatores associados. J Pediatr [Rio de Janeiro] 1995; 71: 77-81.

15. OMS (Organização Mundial da Saúde). Evidencias científicas dos dez passos para o sucesso no aleitamento materno. Brasília (DF): A Organização; 2001.

16. Araújo MFM, Maranhão AGK. Iniciativas do governo em prol do aleitamento materno. In: Rego JD. Aleitamento materno: um guia para pais e familiares. São Paulo: Atheneu; 2002. p. 313-22.

Recebido em 8 de janeiro de 2003

Versão final reapresentada em 18 de março de 2003

Aprovado em 28 de abril de 2003 